\title{
Current Status of and Prospects for the English Medical Journal Surgery Today
}

\author{
Yoshiniko Maehara and Yoshiniro KakejI \\ Department of Surgery and Science, Graduate School of Medical Sciences, Kyushu University, 3-1-1 Maidashi, Higashi-ku, \\ Fukuoka 812-8582, Japan
}

Key words Publication history $\cdot$ Submissions $\cdot$ Future prospects $\cdot$ Impact Factor

\section{History of Surgery Today}

The original official English journal of the Japan Surgical Society, the Japanese Journal of Surgery, was first published in 1971. Initially a quarterly and since 1981 a bimonthly (six issues annually), the journal is now indexed in the Current Contents database and receives an impact factor. After undergoing changes to its cover design and submission guidelines, from 1991 the journal has been published by Springer under the name Surgery Today. The journal is now a monthly, having seen increases in the number of annual submissions under the guidance of each editor-in-chief to date (Fig. 1). In 2003, free-of-charge access to the online version was granted to members of the Japan Surgical Society. In 2006, the journal's submission and peer-review system was computerized. In 2008, the number of annual submissions exceeded 1,000 (reaching 1,101), increasing to more than 1,200 in 2009. The journal has come to be one of the leading English medical journals in Japan. In 2009 , the acceptance rates were $29 \%$ for clinical original papers, $25 \%$ for experimental original papers, and $15 \%$ for case reports. System computerization resulted in a shorter average time required for peer review between receipt of submission and final decision on acceptance or rejection, i.e., 53 days in 2009 compared with 90 days in 2008 , in cases of acceptance.

Reprint requests to: Y. Maehara, Chair, Clinical Study Promotion Committee, Japan Surgical Society; Editor-in-Chief, Surgery Today

This editorial is adapted from an article by the same title that appeared in the Journal of Japan Surgical Society 2010;111(3).

\section{Current Status of Submissions}

In 2009, Surgery Today received 1,234 submissions from 46 countries worldwide. Of the total, $76 \%$ were from Asia, with Japan accounting for 36\%; 19\% were from Europe; and the remainder were from the United States, Africa, and Australia, extending over five continents.

Surgery Today covers a wide range of content, from general surgery to specialized surgical fields by organ. By surgical site, the volume leader is the large intestine $(21 \%)$, followed by stomach (15\%), lung (11\%), liver (10\%) and pancreas $(9 \%)$. Submission rates have also been high for these sites in recent years. By type of contribution, in 2009, review articles stood at $4 \%$, clinical original papers at $24 \%$, experimental original papers at $6 \%$, and case reports at $61 \%$. Quality review articles have been contributed by members of the Japan Surgical Society and leading figures in each field of surgery. At the same time, in terms of providing opportunities for contributing to an English journal, case report submissions have an educational aspect for younger surgeons who have encountered valuable cases. We encourage younger surgeons to write and submit English reports to us.

In an attempt to further improve the quality of Surgery Today as an English medical journal, we have reviewed our ethical rules for contribution, prohibited double contribution and duplicate publication, and revised the authors' statement of compliance to the above rules - which statement must accompany each submission - to document the authors' ethical and moral commitments.

As an indicator of the quality of a medical journal, the impact factor is calculated using the number of citations of articles published in a journal during the preceding two years. For Surgery Today, the impact factor was 0.679 in 2007, which increased to 0.804 in 2008, and rose above 1 (at 1.050) in 2009 (Fig. 2). With the aim of improving our journal's impact factor, we have increased 

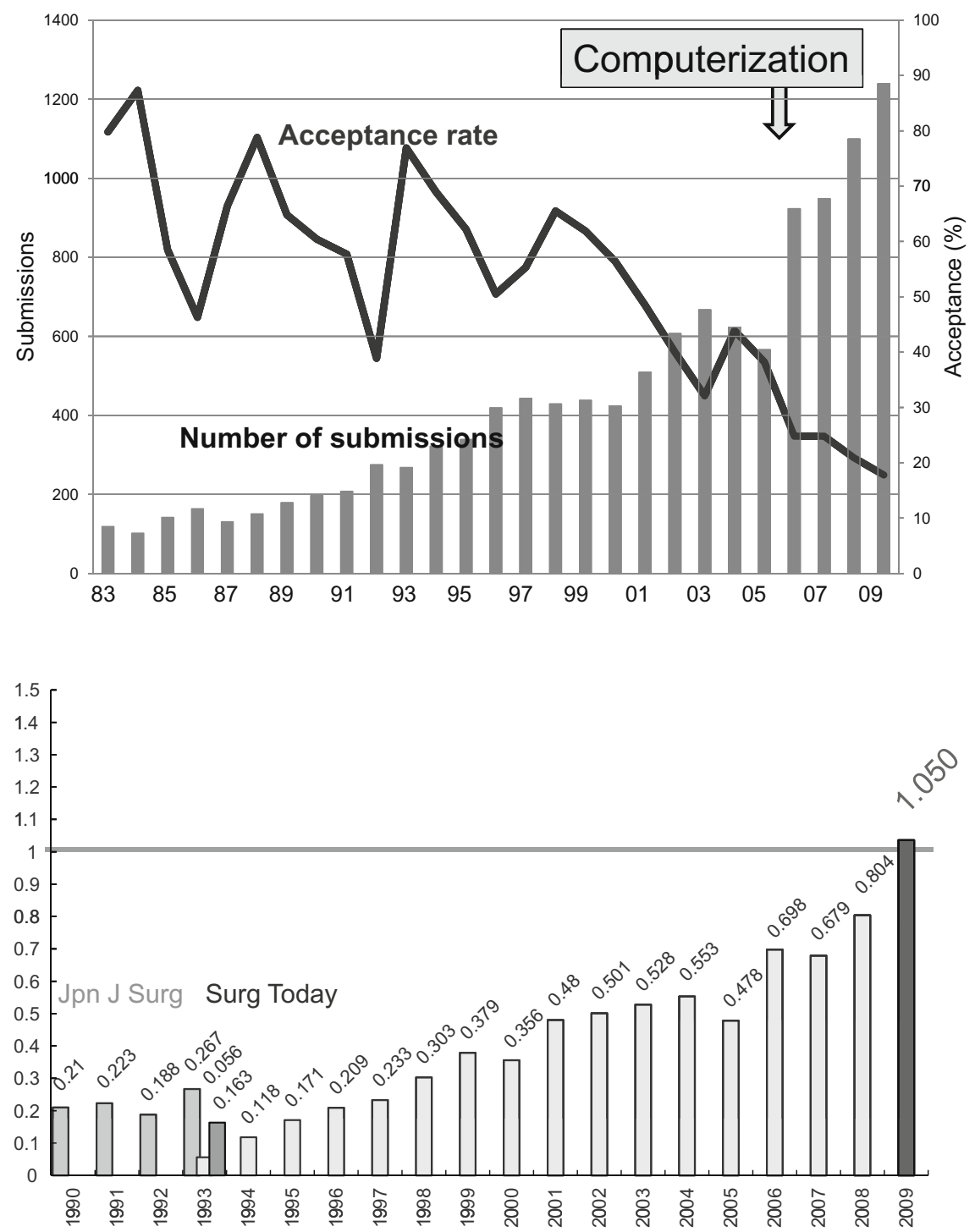

Fig. 1. Number of submissions and acceptance rate for Surgery Today. Adapted with permission from Maehara ${ }^{32}$
Fig. 2. Surgery Today Impact Factors. Adapted with permission from Maehara ${ }^{32}$ the proportion of original papers, both clinical and experimental, and review articles, which are frequently cited. We will continue our efforts to disseminate information and evidence through quality papers, articles, and reports.

\section{Contributions Published in Recent Years}

\section{Gastrointestinal}

Recent contributions include reports concerning surgical techniques such as triangulating stapling technique for esophagogastric anastomosis ${ }^{1}$ and total mesorectal excision for rectal cancer. ${ }^{2}$ Also noted are a report on perioperative pain management by patient-controlled epidural analgesia ${ }^{3}$ and a prospective randomized trial report demonstrating the utility of preoperative oral antibiotic treatment for the prevention of postoperative infections. ${ }^{4}$ Multiple reports were received regarding surgical site infections. ${ }^{5,6}$ Other reports include those on chemotherapy for gastric and colorectal cancer ${ }^{7}$ and for small bowel cancer, ${ }^{8}$ and on a nude mouse model experiment for tumor vascular normalization by antiangiogenic receptor tyrosine kinase inhibitor, ${ }^{9}$ providing a range of topics.

\section{Heart and Vessels}

Reports from the clinical frontline include clinical results of commissure plication annuloplasty for mitral regurgitation in childre ${ }^{10}$ and predictors of allogeneic blood transfusion in adult elective cardiac surgery after preoperative autologous blood donation. ${ }^{11}$ Another timely report ${ }^{12}$ is on the clinical outcome of perioperative nonpermanent vena cava filter placement in the 
treatment of deep venous thrombosis, a condition the seriousness of which has become increasingly apparent. Other reports include risk factor evaluation for the severely ischemic limb and findings from some basic animal experiments, such as anti-inducible costimulator antibody immunotherapy for cardiac allograft rejection $^{13}$ and inhibition of intimal hyperplasia.

\section{Respiratory, Mammary Gland, and Endocrine}

Articles on thoracoscopic lung surgery, which are steadily increasing in number, include a report on the clinical pathway of the procedure. ${ }^{14}$ Many other reports of pathological mechanisms have been submitted - mechanisms such as the macrophage migration inhibitory factor expressed in lung cancer tissue ${ }^{15}$ and bronchial healing after lobar lung transplantation. ${ }^{16}$ In a case-control study that assessed the usefulness of adjuvant therapy with a bacillus Calmette-Guérin cell wall skeleton, following surgery for non-small cell lung cancer, the survival rate was higher in patients with adjuvant therapy than in those without it, but the difference was not significant. ${ }^{17} \mathrm{~A}$ report on sentinel lymph node biopsy after preoperative chemotherapy for breast cancer is also noteworthy. ${ }^{18}$

\section{Liver and Transplantation}

Reports on liver transplantation ${ }^{19,20}$ are increasing. Final results have been submitted on a randomized multicenter trial that investigated surgery versus radiochemotherapy in the treatment of resectable locally invasive pancreatic cancer. ${ }^{21}$ Surgical techniques are the topics of many articles, including a multicenter study showing that extrahepatic bile duct resection did not contribute to better prognosis in advanced gallbladder carcinoma ${ }^{22}$ along with reports on the significance of aberrant right hepatic artery ${ }^{23}$ and of pylorus preservation ${ }^{24}$ in pancreaticoduodenectomy. In addition to the above-mentioned clinical reports that were submitted, basic research findings have been reported, such as the effect of FTY720 in small bowel transplantation $^{25}$ and of endothelial molecular markers in the evaluation of acute pancreatitis severity. ${ }^{26}$

\section{General}

Findings have been reported from rat model experiments targeting clinical developments, such as changes in A-type natriuretic peptide and receptors in a septic rat model $^{27}$ and reduced perioperative immune response in endoscopic surgery compared with open surgery. ${ }^{28}$ Results of a knockout mouse experiment evaluating cyclophosphamide-induced tolerance have been presented as well. ${ }^{29}$ Also of clinical significance are reports on crush syndrome due to drug-induced compartment syndrome $^{30}$ and on an indicator of potential morbidity and mortality risks in patients admitted to the intensive care unit. ${ }^{31}$

\section{Need for Clinical Research Findings and Evidence}

In Japan, the need for large-scale multicenter clinical trials in clinical surgical research is expected to further increase. The Clinical Study Promotion Committee of the Japan Surgical Society has been playing a pivotal role in addressing this issue, informing relevant personnel of the importance of multicenter clinical trials at clinical research seminars held in conjunction with the Japan Surgical Society's regular academic meetings. With the support of a Health and Labour Sciences Research Grant, the Committee has proceeded with clinical studies including a "Multicenter prospective randomized trial about the clinical effect of absorbable suture materials on surgical site infection in digestive surgery, hepatic resection, and pancreatoduodenectomy" and "Efficacy of surgery versus radiofrequency ablation (RFA) on primary hepatocellular carcinoma: a multicenter randomized controlled trial."

We, the editors of Surgery Today, are determined to continue our efforts in maintaining the reputation of a quality English medical journal that receives submissions from around the world and provides valuable evidence in the field of surgery, and thus contributes valuable information of benefit to surgeons across all national borders. We look forward to receiving submissions of quality papers from members of surgical societies worldwide.

Yoshihiko Maehara Chair, Clinical Study Promotion Committee, Japan Surgical Society Editor-in-Chief, Surgery Today

\section{References}

1. Toh Y, Sakaguchi Y, Ikeda O, Adachi E, Ohgaki K, Yamashita $\mathrm{Y}$, et al. The triangulating stapling technique for cervical esophagogastric anastomosis after esophagectomy. Surg Today 2009; 39:201-6.

2. Kusunoki M, Inoue Y, Yanagi H. Simplification of total mesorectal excision with colonic J-pouch anal anastomosis for middle and lower rectal cancer: one surgeon's experience. Surg Today 2008; 38:691-9.

3. Saeki H, Ishimura H, Higashi H, Kitagawa D, Tanaka J, Maruyama R, et al. Postoperative management using intensive patient-controlled epidural analgesia and early rehabilitation after an esophagectomy. Surg Today 2009;39:476-80.

4. Ishibashi K, Kuwabara K, Ishiguro T, Ohsawa T, Okada N, Miyazaki T, et al. Short-term intravenous antimicrobial prophylaxis in combination with preoperative oral antibiotics on surgical site infection and methicillin-resistant Staphylococcus aureus infection in elective colon cancer surgery: Results of a prospective randomized trial. Surg Today 2009;39:1032-39. 
5. Itabashi M, Ikeuchi H, Araki T, Kono T, Nakamura T, Takesue $\mathrm{Y}$, et al. Effectiveness of leukocytapheresis in suppressing the occurrence of surgical site infections. Surg Today 2008;38: $609-17$.

6. Watanabe A, Kohnoe S, Shimabukuro R, Yamanaka T, Iso Y, Baba $\mathrm{H}$, et al. Factors associated with surgical site infection in upper and lower gastrointestinal surgery. Surg Today 2008;38: 404-12.

7. Hata F, Sasaki K, Hirata K, Yamamitsu S, Shirasaka T. Efficacy of a continuous venous infusion of fluorouracil and daily divided dose cisplatin as adjuvant therapy in resectable colorectal cancer: A prospective randomized trial. Surg Today 2008;38:623-32.

8. Suenaga M, Mizunuma N, Chin K, Matsusaka S, Shinozaki E, Oya M, et al. Chemotherapy for small-bowel adenocarcinoma at a single institution. Surg Today 2009;39:27-31.

9. Ohta M, Kawabata T, Yamamoto M, TanakaT, Kikuchi H, Hiramatsu Y, et al. TSU68, an antiangiogenic receptor tyrosine kinase inhibitor, induces tumor vascular normalization in a human cancer xenograft nude mouse model. Surg Today 2009;39: 1046-53.

10. Kajihara N, Imoto Y, Kan-o M, Sakamaoto M, Ochiai Y, Joo K, et al. Clinical results of commissure plication annuloplasty for mitral regurgitation in children. Surg Today 2009;39:110-4.

11. Takami Y, Masumoto H. Predictors of allogenic blood transfusion in elective cardiac surgery after preoperative autologous blood donation. Surg Today 2009;39:306-9.

12. Ishihara K, Hiromatsu S, Shintani Y, Kanaya K, Mikasa K, Aoyagi S. Clinical outcome of perioperative nonpermanent vena cava filter placement in patients with deep venous thrombosis or blood stasis of the vein. Surg Today 2009;39:764-9.

13. Pan XC, Guo L, Deng YB, Naruse K, Kimura H, Sugawara Y, et al. Further study of anti-ICOS immunotherapy for rat cardiac allograft rejection. Surg Today 2008;38:815-25.

14. Okita A, Yamashita M, Abe K, Nagai C, Matsumoto A, Akehi $\mathrm{M}$, et al. Variance analysis of a clinical pathway of video-assisted single lobectomy for lung cancer. Surg Today 2009;39:104-9.

15. Hamatake M, Yoshino I, Tomiyasu M, Miura N, Okazaki H, Ohba T, et al. Intratumoral expression of macrophage migration inhibitory factor is correlated with serum C-reactive protein and interleukin-6 in patients with non-small cell lung cancer. Surg Today 2008;38:921-5.

16. Toyooka S, Yamane M, Oto T, Sano Y, Okazaki M, Date H. Bronchial healing after living-donor lobar lung transplantation. Surg Today 2009;39:938-43.

17. Kodama K, Higashiyama M, Takami K, Oda K, Okami J, Maeda J. Innate immune therapy with a bacillus Calmette-Guérin cell wall skeleton after radical surgery for non-small cell lung cancer: A case-control study. Surg Today 2009;39:194-200.

18. Hino M, Sano M, Sato N, Homma K. Sentinel lymph node biopsy after neoadjuvant chemotherapy in a patient with operable breast cancer. Surg Today 2008;38:585-91.

19. Ikegami T, Sanchez EQ, Uemura T, Narasimhan G, Masannat O, Chinnakotla S, et al. Liver transplantation for cystic fibrosis in adults. Surg Today 2008;38:26-9.
20. Eguchi S, Takatsuki M, Hidaka M, Tajima Y, Kanematsu T. Evolution of living donor liver transplantation over 10 years: experience of a single center. Surg Today 2008;38:795800.

21. Doi R, Imamura M, Hosotani R, Imaizumi T, Hatori T, Takasaki $\mathrm{K}$, et al. Surgery versus radiochemotherapy for resectable locally invasive pancreatic cancer: final results of a randomized multiinstitutional trial. Surg Today 2008;38:1021-8.

22. Araida T, Higuchi R, Hamano M, KoderaY, Takeshita N, Ota T, et al. Should the extrahepatic bile duct be resected or preserved in R0 radical surgery for advanced gallbladder carcinoma? Results of a Japanese Society of Biliary Surgery Survey: a multicenter study. Surg Today 2009;39:770-9.

23. Jah A, Jamieson N, Huguet E, Praseedom R. The implications of the presence of an aberrant right hepatic artery in patients undergoing a pancreaticoduodenectomy. Surg Today 2009;39: 669-74.

24. Tani M, Kawai M, Hirono S, Ina S, Miyazawa M, Fujita Y. Pylorus-preserving pancreaticoduodenectomy versus conventional pancreaticoduodenectomy for pancreatic adenocarcinoma. Surg Today 2009;39:219-24

25. Sugito K, Inoue M, Ikeda T, Hagiwara N, Koshinaga T, Kusafuka T. Effect of FTY720 and ex vivo graft irradiation in rat small bowel transplantation: expression of mucosal addressin cell adhesion molecule-1. Surg Today 2008;38:38-41.

26. Ida S, Fujimura Y, Hirota M, Imamura Y, Ozaki N, Suyama K, et al. Significance of endothelial molecular markers in the evaluation of the severity of acute pancreatitis. Surg Today 2009;39: 314-9.

27. Maeshiro K, Takamori S, Mifune H, Matsuo T, Kimura NY, Honda $\mathrm{J}$, et al. Changes in A-type natriuretic peptide and its receptors induced by a neutral endopeptidase inhibitor in a rat model of sepsis. Surg Today 2008;38:130-4.

28. Ito Y, Oda M, Tsunezuka Y, Matsumoto I, Ishikawa N, Kawakami $\mathrm{K}$, et al. Reduced perioperative immune response in videoassisted versus open surgery in a rat model. Surg Today 2009;39:682-8

29. Onzuka T, Shimizu I, Tomita Y, Iwai T, Okano S, Tominaga R. Application of cyclophosphamide-induced tolerance in $\alpha 1,3-$ galactosyltransferase knockout mice pre-sensitized with Gala13Galb-4-GlcNAc antigens. Surg Today 2008;38:807-14.

30. Golling M, Fonouni H, Mehrabi A, McArthur N, Huber FX. Crush syndrome due to drug-induced compartment syndrome: A rare condition not to be overlooked. Surg Today 2009;39: $558-65$.

31. Chan KS, Tan CK, Fang CS, Tsai CL, Hou CC, Cheng KC, et al. Readmission to the intensive care unit: an indicator that reflects the potential risks of morbidity and mortality of surgical patients in the intensive care unit. Surg Today 2009;39:295-9.

32. Maehara Y. Current status of and prospects for the English medical journal Surgery Today (in Japanese). J Jpn Surg Soc 2010;111(3):49-50. 